\title{
The effect of neuraxial anesthesia on cancer recurrence and survival after cancer surgery: an updated meta-analysis
}

\author{
Meilin Weng ${ }^{1}$, Wankun Chen ${ }^{1}$, Wenting Hou ${ }^{1}$, Lihong $\mathrm{Li}^{1}$, Ming Ding ${ }^{2}$ and Changhong \\ Miao $^{1}$ \\ ${ }^{1}$ Department of Anesthesiology, Fudan University Shanghai Cancer Centre, Department of Oncology, Shanghai Medical \\ College Fudan University, Shanghai, China \\ 2 Department of Anesthesiology, Zhongshan Hospital, Fudan University, Shanghai, China \\ Correspondence to: Changhong Miao, email: whitedolphin2007@hotmail.com \\ Ming Ding, email: ding.ming@zs-hospital.sh.cn
}

Keywords: neuraxial anesthesia, general anesthesia, cancer recurrence, survival, cancer outcome

Received: October 30, $2015 \quad$ Accepted: January 28, $2016 \quad$ Published: February 24, 2016

\section{ABSTRACT}

Several animal and observational studies have evaluated the effects of neuraxial anesthesia on the recurrence and survival of cancer surgery; studies reported benefit, whereas others did not. To provide further evidence that neuraxial anesthesia(combined with or without general anesthesia (GA))may be associated with reduced cancer recurrence and long-term survival after cancer surgery, we conducted this meta-analysis. A total of $\mathbf{2 1}$ studies were identified and analyzed, based on searches conducted using PubMed, Web of Science, EMBASE database and the Cochrane Database of Systematic Reviews. After data abstraction, adjusted hazard ratios (HR) with $95 \%$ confidence intervals (CIs) were used to assess the impact of neuraxial anesthesia (combined with or without GA) and GA on oncological outcomes after cancer surgery. For overall survival (OS), a potential association between neuraxial anesthesia and improved OS (HR 0.853, CI 0.741-0.981, $P=$ 0.026 , the random-effects model) was observed compared with GA. Specifically, we found a positive association between neuraxial anesthesia and improved OS in colorectal cancer (HR 0.653, CI 0.430-0.991, $P=0.045$, the random-effects model). For recurrence-free survival (RFS), a significant association between neuraxial anesthesia and improved RFS (HR 0.846, CI 0.718-0.998, $P=0.047$, the randomeffects model) was detected compared with GA. Our meta-analysis suggests that neuraxial anesthesia may be associated with improved OS in patients with cancer surgery, especially for those patients with colorectal cancer. It also supports a potential association between neuraxial anesthesia and a reduced risk of cancer recurrence. More prospective studies are needed to elucidate whether the association between neuraxial use and survival is causative.

\section{INTRODUCTION}

Surgical resection is essential to the treatment of cancer. However, surgery itself has the potential to promote the development of metastases and reduce subsequent survival $[1,2]$. Inhaled anesthetics and intravenous opioids may contribute to the suppression of cell-mediated immunity by decreasing the activity of natural killer (NK) cells [3-6]. Neuraxial anesthesia (including epidural anesthesia or spinal anesthesia) combined with or without general anesthesia (GA)can attenuate the neuroendocrine stress response and prevent immunosuppression. In addition, it also decreases the requirement for inhaled anesthetics and opioids $[7,8,23$, 24]. Therefore, neuraxial anesthesia may be beneficial for patients undergoing cancer surgery.

Recently, several retrospective studies for prostate and ovarian cancer have suggested a reduction in cancer recurrence and metastasis in patients receiving perioperative neuraxial analgesia $[24,28]$. In contrast to 
these studies, the authors found that the use of neuraxial analgesia for perioperative pain control during colorectal cancer and prostate cancer surgery was not associated with a decreased cancer recurrence and metastasis [10, 12$14,22,25,26]$. Due to selection bias and other variation factors, the results of these findings are conflicting rather than conclusive.

Pei et al. have performed a meta-analysis to investigate the association between epidural anesthesia and prognosis of cancer patient after surgery [30]. However, they excluded several eligible studies (e.g., the studies by Scavonetto et al. [12], Lacassie et al. [16], Myles et al. [18], Binczak et al. [19], Lai et al. [20], Merquiol et al. [21], and Forget et al. [26]). To provide further evidence that neuraxial anesthesia (combined with or without GA) may be associated with reduced cancer recurrence and long-term survival after cancer surgery, we conducted this meta-analysis.

\section{RESULTS}

\section{Basic characteristics}

After a careful and thorough search, 21 eligible studies [9-29] met the inclusion criteria (Table 1). These studies included approximately 15,160 cases in the neuraxial anesthesia group and approximately 36,460

\section{PRISMA 2009 Flow Diagram}
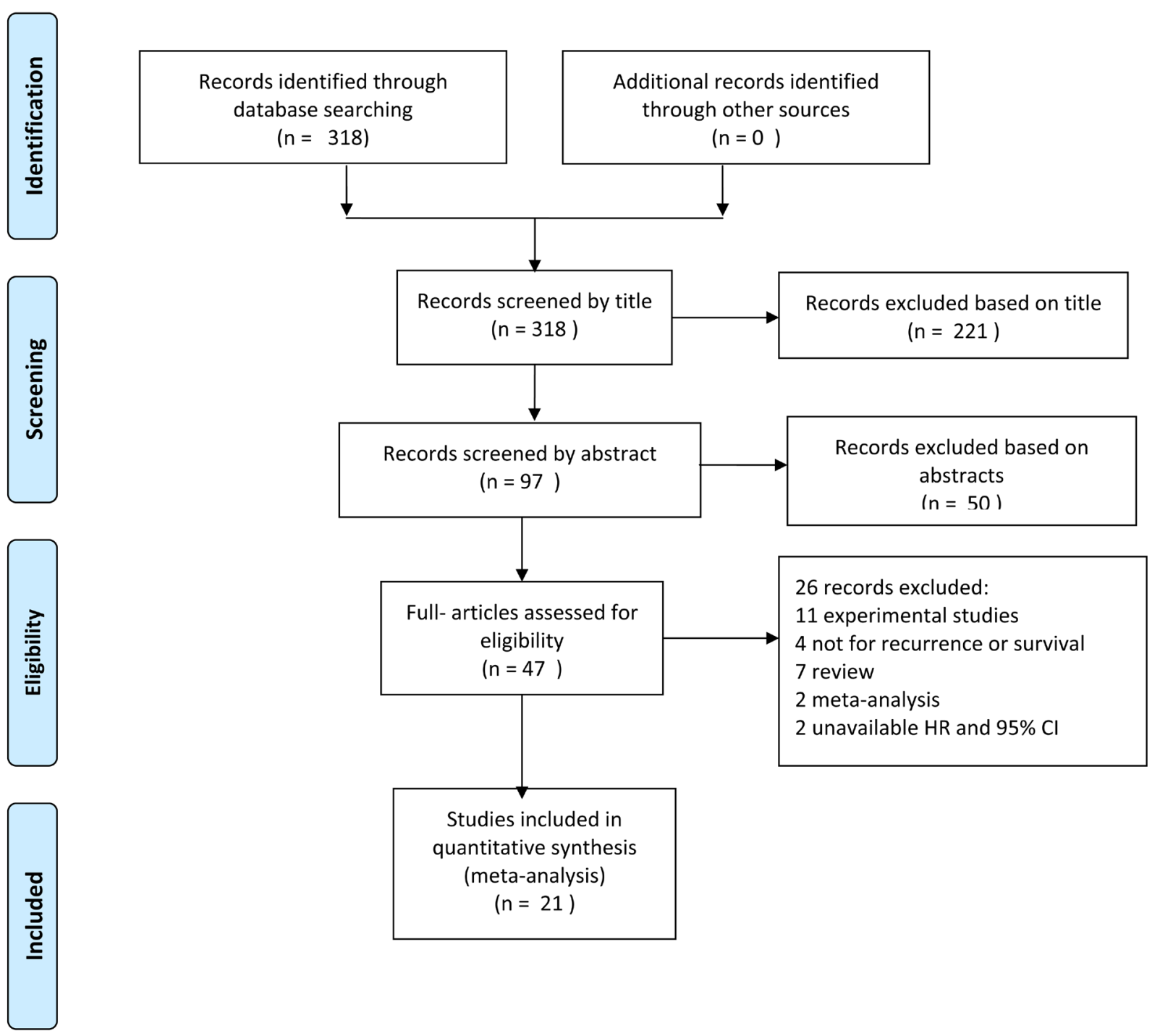

Figure 1: PRISMA 2009 flow diagram 
Table 1: Characteristics of eligible studies for meta-analysis

\begin{tabular}{|c|c|c|c|c|c|c|c|c|c|}
\hline Author & Year & Cancer type & Design type & Survival & neuraxial & No neuraxial & HR & $95 \% \mathrm{Cl}$ & Quality* \\
\hline R.Christopherson-I [9] & 2008 & $\begin{array}{l}\text { Non- metastatic } \\
\text { Colon cancer }\end{array}$ & prospective & Overall survival & 85 & 92 & 0.216 & $0.065-0.718$ & 7 \\
\hline $\begin{array}{l}\text { R.Christopherson-II } \\
\text { [9] }\end{array}$ & 2008 & $\begin{array}{l}\text { Metastatic } \\
\text { Colon cancer }\end{array}$ & prospective & Overall survival & 85 & 92 & 0.699 & $0.395-1.236$ & 7 \\
\hline K.C. Cummings [10] & 2011 & Colorectal cancer & retrospective & Overall Survival & 9670 & 32481 & 0.91 & $0.87-0.94$ & 8 \\
\hline A.Gupta-I [11] & 2011 & Colon caner & retrospective & Overall Survival & 562 & 93 & 0.82 & $0.3-2.19$ & 6 \\
\hline A.Gupta-II [11] & 2011 & rectal caner & retrospective & Overall Survival & 562 & 93 & 0.45 & $0.22-0.90$ & 6 \\
\hline F.Scavonetto [12] & 2004 & Prostate cancer & retrospective & All cause death & 1642 & 1642 & 1.32 & $1.00-1.74$ & 8 \\
\hline P.Y.Wuethrich [13] & 2010 & Prostate cancer & retrospective & Overall survival & 103 & 158 & 0.61 & $0.29-1.28$ & 7 \\
\hline P.Y.Wuethrich [14] & 2013 & Prostate cancer & retrospective & Overall survival & 67 & 81 & 1.79 & $0.95-3.39$ & 7 \\
\hline L.Lin [15] & 2011 & Ovarian cancer & retrospective & Overall survival & 106 & 37 & 0.824 & $0.699-0.930$ & 6 \\
\hline H.J.Lacassie [16] & 2013 & Ovarian cancer & prospective & Overall survival & 37 & 43 & 0.73 & $0.36-1.52$ & 6 \\
\hline J.G.Hiller [17] & 2014 & $\begin{array}{l}\text { Gastro-oesophageal } \\
\text { cancer }\end{array}$ & retrospective & Overall survival & 97 & 43 & 0.42 & $0.21-0.83$ & 7 \\
\hline P.S.Myles [18] & 2011 & Abdominal cancer & prospective & Overall survival & 230 & 216 & 0.95 & $0.77-1.18$ & 7 \\
\hline M. Binczak [19] & 2013 & Abdominal cancer & retrospectivve & Overall survival & 69 & 63 & 0.69 & $0.43-1.09$ & 6 \\
\hline R.Lai [20] & 2011 & Hepatocellular caner & retrospective & Overall survival & 62 & 117 & 1.26 & $0.81-1.97$ & 7 \\
\hline F.Merquiol [21] & 2013 & $\begin{array}{l}\text { Laryngeal and } \\
\text { hypopharyngeal } \\
\text { cancer }\end{array}$ & retrospective & Overall survival & 111 & 160 & 0.61 & $0.39-0.96$ & 7 \\
\hline A.Gottschalk [22] & 2010 & Colorectal cancer & retrospective & $\begin{array}{l}\text { Recurrence } \\
\text { free survival }\end{array}$ & 256 & 253 & 0.82 & $0.49-1.35$ & 7 \\
\hline K.C.Cummings [10] & 2011 & Colorectal cancer & retrospective & \begin{tabular}{|l|} 
Recurrence \\
free survival
\end{tabular} & 9670 & 32481 & 1.05 & $0.95-1.15$ & 8 \\
\hline A.K.Exadaktylos [23] & 2006 & Breast cancer & retrospective & $\begin{array}{l}\text { Recurrence } \\
\text { free survival } \\
\end{array}$ & 50 & 79 & 0.21 & $0.06-0.71$ & 7 \\
\hline F.Scavonetto [12] & 2004 & Prostate cancer & retrospective & $\begin{array}{l}\text { Recurrence } \\
\text { free survival }\end{array}$ & 1642 & 1642 & 1.00 & $0.83-1.21$ & 8 \\
\hline B.Biki [24] & 2008 & Prostate cancer & retrospective & $\begin{array}{l}\text { Recurrence } \\
\text { free survival } \\
\end{array}$ & 102 & 123 & 0.43 & $0.22-0.83$ & 6 \\
\hline B.C.H.Tsui [25] & 2010 & Prostate cancer & prospective & $\begin{array}{l}\text { Disease free } \\
\text { survival }\end{array}$ & 49 & 50 & 1.33 & $0.64-2.77$ & 6 \\
\hline P.Forget [26] & 2010 & Prostate cancer & retrospective & $\begin{array}{l}\text { Recurrence } \\
\text { free survival }\end{array}$ & 578 & 533 & 0.84 & $0.52-1.17$ & 7 \\
\hline P.Y.Wuethrich [13] & 2010 & Prostate cancer & retrospective & $\begin{array}{l}\text { Recurrence } \\
\text { free survival }\end{array}$ & 103 & 158 & 1.14 & $0.84-1.54$ & 7 \\
\hline P.Y.Wuethrich [14] & 2013 & Prostate cancer & retrospective & $\begin{array}{l}\text { Distant } \\
\text { Recurrence } \\
\text { free survival }\end{array}$ & 67 & 81 & 0.58 & $0.27-1.29$ & 7 \\
\hline K.S.Tseng [27] & 2014 & Prostate cancer & retrospective & $\begin{array}{l}\text { Recurrence } \\
\text { free survival }\end{array}$ & 1166 & 798 & 0.91 & $0.70-1.18$ & 7 \\
\hline $\begin{array}{l}\text { G.S.de.Oliveira.Jr-I } \\
{[28]}\end{array}$ & 2011 & Ovarian cancer & retrospective & $\begin{array}{l}\text { Recurrence } \\
\text { free survival }\end{array}$ & 26 & 127 & 0.37 & $0.19-0.73$ & 7 \\
\hline $\begin{array}{l}\text { G.S.de.Oliveira.Jr-II } \\
{[28]}\end{array}$ & 2011 & Ovarian cancer & retrospective & $\begin{array}{l}\text { Recurrence } \\
\text { free survival }\end{array}$ & 29 & 127 & 0.86 & $0.52-1.41$ & 7 \\
\hline H.J.Lacassie [16] & 2013 & Ovarian cancer & prospective & $\begin{array}{l}\text { Recurrence } \\
\text { free survival }\end{array}$ & 37 & 43 & 0.73 & $0.40-1.31$ & 6 \\
\hline P.S.Myles [18] & 2011 & abdominal & prospective & $\begin{array}{l}\text { Recurrence } \\
\text { free survival }\end{array}$ & 230 & 216 & 0.95 & $0.76-1.17$ & 7 \\
\hline M.Binczak [19] & 2013 & Abdominal cancer & retrospective & $\begin{array}{l}\text { Recurrence } \\
\text { free survival }\end{array}$ & 69 & 63 & 0.81 & $0.52-1.27$ & 6 \\
\hline J.G.Hiller [17] & 2014 & $\begin{array}{l}\text { Gastro-oesophageal } \\
\text { cancer }\end{array}$ & retrospective & $\begin{array}{l}\text { Recurrence } \\
\text { free survival }\end{array}$ & 97 & 43 & 0.33 & $0.17-0.63$ & 7 \\
\hline R.Lai [20] & 2011 & Hepatocellular cancer & retrospective & $\begin{array}{l}\text { Recurrence } \\
\text { free survival }\end{array}$ & 62 & 117 & 4.31 & $2.24-8.29$ & 7 \\
\hline F.Merquiol [21] & 2013 & $\begin{array}{l}\text { Laryngeal and } \\
\text { hypopharyngeal } \\
\text { cancer }\end{array}$ & retrospective & $\begin{array}{l}\text { Cancer free } \\
\text { survival }\end{array}$ & 111 & 160 & 0.49 & $0.25-0.96$ & 7 \\
\hline H.Ismail [29] & 2010 & Cervical cancer & retrospective & $\begin{array}{l}\text { Local or } \\
\text { systemic } \\
\text { recurrence }\end{array}$ & 63 & 69 & 0.95 & $0.54-1.67$ & 6 \\
\hline
\end{tabular}

* evaluated by the 9-star Newcastle-Ottawa Scale. 
Table 2: Pooled hazard ratios for overall survival and recurrence-free survival

\begin{tabular}{|l|l|l|l|l|}
\hline Pooled analysis & $\begin{array}{l}\text { Study } \\
\text { number }\end{array}$ & HR (95\% CI) & P for difference & $\begin{array}{l}\text { for heterogeneity and } \\
\text { I-squared }\end{array}$ \\
\hline Overall Survival & 15 & $0.853(0.741-0.981)$ & 0.026 & 0.001 and $61.3 \%$ \\
\hline All groups & 5 & $0.653(0.430-0.991)$ & 0.045 & 0.038 and $60.6 \%$ \\
\hline In colorectal cancer & $1.194(0.735-1.941)$ & 0.474 & 0.085 and $59.5 \%$ \\
\hline In prostate cancer & 3 & \multicolumn{5}{l|}{} \\
\hline Recurrence-free Survival & 19 & $0.846(0.718-0.998)$ & 0.047 & 0.000 and $71.4 \%$ \\
\hline All groups & 7 & $0.640(0.396-1.033)$ & 0.068 & 0.127 and $39.7 \%$ \\
\hline In prostate cancer & 7 & 0.133 and $50.4 \%$ \\
\hline In ovarian cancer & 3 &
\end{tabular}

cases in the GA group. The studies were published between 2004 and 2014. Overall survival (OS) and recurrence-free survival (RFS) were defined as two end points, respectively. OS was defined from surgery to death for any reason. RFS was defined from surgery to the first occurrence of disease progression or relapse due to the primary cancer.

There were 15 studies [9-21] that involved OS, 7 of which $[9-12,15,17,21]$ demonstrated a positive relationship between neuraxial anesthesia and improved OS. Five studies [9-11] were on colorectal cancer, and 3 studies [12-14] were on prostate cancer. The remaining cancer types investigated were ovarian cancer, gastrooesophageal cancer, laryngeal and hypopharyngeal cancer, abdominal cancer, and hepatocellular cancer. [15-21]

There were 19 studies [10, 12-14, 16-29] that involved RFS, 6 of which [17, 20, 21, 23, 24, 28] showed a positive relationship between neuraxial anesthesia and improved RFS. Seven studies [12-14, 24-27] were on prostate cancer, and 3 studies $[16,28]$ were on ovarian cancer. The remaining cancer types investigated were breast cancer, colorectal cancer, gastro-oesophageal cancer, abdominal cancer, laryngeal and hypopharyngeal cancer, hepatocellular cancer, and cervical cancer [17-21, 29].

\section{Association between neuraxial anesthesia and OS}

Significant heterogeneity was detected in the HRs for OS (heterogeneity chi-squared $=36.16, P=0.001$, I-squared $=61.3 \%$ ), so the random-effects model was used to analyze these data. A significant association between neuraxial anesthesia and improved OS was then observed compared with GA (HR 0.853, CI 0.741-0.981, $P=0.026$ ) (Table 2, Figure 2A). The further sensitivity analysis also proved that our results were robust and stable (Figure 3A). Because 5 studies [9-11] were on colorectal cancer, a subgroup analysis was conducted specifically for them. An obvious association between neuraxial anesthesia and improved OS was found in colorectal cancer (HR 0.653, CI 0.430-0.991, $P=0.045$ ) (Table 2, Figure 2B). No significant association between neuraxial anesthesia and improved OS was detected in prostate cancer [12-14]
(Table 2).

\section{Association between neuraxial anesthesia and RFS}

Apparent heterogeneity was observed in the HRs for RFS (heterogeneity chi-squared $=62.98, P=0.000$, I-squared $=71.4 \%$ ), so the random-effects model was used to analyze these data. A potential association between neuraxial anesthesia and improved RFS was then observed compared with GA (HR 0.846, CI 0.718-0.998, $P=0.047$ ) (Table 2, Figure 2C). A further sensitivity analysis also indicated that our results were robust and stable (Figure 3B). Subgroup analyses were performed by prostate cancer [12-14, 24-27] and ovarian cancer [16, 28]. No significant association between neuraxial anesthesia and improved RFS was found in prostate cancer and ovarian cancer (Table 2).

\section{Publication bias}

The funnel plot was used to evaluate publication bias. Moreover, Egger's test and Begg's test showed no evidence of publication bias in OS $(P=0.198$ and $P=$ 0.181 , respectively), and RFS $(P=0.142$ and $P=0.132$, respectively) (Figure 4A, 4B).

\section{DISCUSSION}

Our results suggest that neuraxial anesthesia maybe associated with improved OS in patients with cancer surgery, especially for those patients with colorectal cancer. The impact of neuraxial anesthesia on recurrence and survival after cancer surgery has been a contentious issue [9-21]. The use of neuraxial anesthetic techniques has been found to be associated with improved OS after colorectal cancer, prostate cancer, gastro-oesophageal cancer, laryngeal and hypopharyngeal cancer, and ovarian cancer surgery $[9-12,15,17,21]$. Some recently published studies, however, did not find any difference in mortality after colorectal cancer, prostate cancer, ovarian cancer, abdominal cancer, and hepatocellular cancer surgery 
A

Study

ID
$\%$

HR $(95 \% \mathrm{Cl}) \quad$ Weight

R.Christopherson-I (2008)

R.Christopherson-II (2008)

K.C. Cummings (2011)

A.Gupta-I (2011)

A.Gupta-II (2011)

F.Scavonetto (2004)

P.Y.Wuethrich (2010)

P.Y.Wuethrich (2013)

L.Lin (2011)

H.J.Lacassie (2013)

J.G.Hiller (2014)

P.S.Mayles (2011)

M. Binczak (2013)

R.Lai (2011)

F.Merquiol (2013)

Overall $(I$-squared $=61.3 \%, p=0.001)$

NOTE: Weights are from random effects analysis

.065
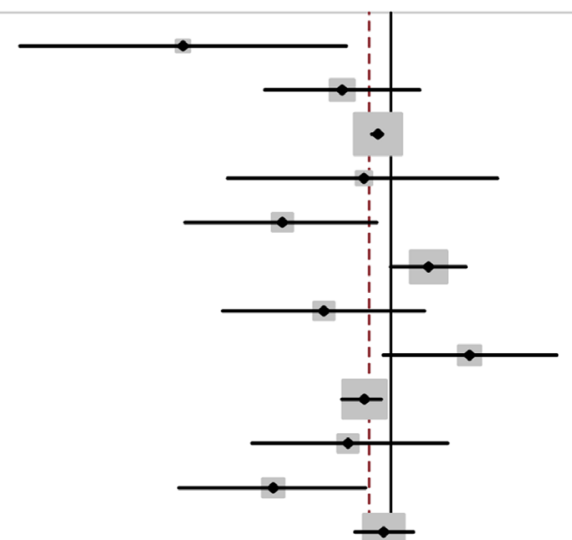

$0.22(0.06,0.72) \quad 1.27$

$0.70(0.40,1.24) \quad 4.54$

$0.91(0.87,0.94) \quad 18.07$

$0.82(0.30,2.19) \quad 1.79$

$0.45(0.22,0.90) \quad 3.25$

$1.32(1.00,1.74) \quad 10.67$

$0.61(0.29,1.28) \quad 2.98$

$1.79(0.95,3.39) \quad 3.83$

$0.82(0.70,0.93) \quad 15.39$

$0.73(0.36,1.52) \quad 3.13$

$0.42(0.21,0.83) \quad 3.39$

$0.95(0.77,1.18) \quad 12.85$

$0.69(0.43,1.09) \quad 6.07$

$1.26(0.81,1.97) \quad 6.44$

$0.61(0.39,0.96) \quad 6.33$

$0.85(0.74,0.98) \quad 100.00$

B

Study

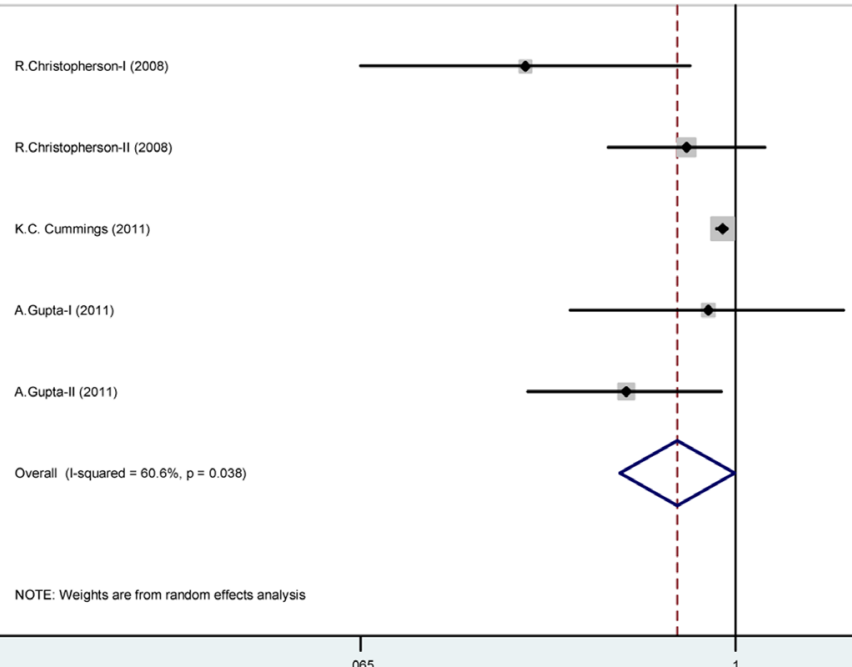

HR $(95 \% \mathrm{Cl}) \quad$ Weight

$0.22(0.06,0.72)$

9.18

$0.70(0.40,1.24)$

$0.91(0.87,0.94) \quad 38.13$

$\begin{array}{ll}0.82(0.30,2.19) & 12.07\end{array}$

$0.45(0.22,0.90)$

$0.65(0.43,0.99) \quad 100.00$ 


Study
ID

Figure 2: Forest plot of meta-analysis. In Figure 2A (overall survival analysis), 2B (overall survival analysis in colorectal cancer) and $2 \mathrm{C}$ (recurrence-free survival analysis), each study is shown by the point estimate of the hazard ratio (HR) and $95 \%$ confidence interval (CIs).

in patients with neuraxial anesthesia compared with those without $[9,11,13,14,16,18-20]$. Our results are consistent with those in a previous meta-analysis in our institution by Chen et al., which confirmed the positive effect of neuraxial anesthesia on cancer survival [37].

Host defense is established as the primary determinant of progression of cancer, [7] and the function of NK cells is the most important component for recognizing and killing tumor cells [38]. Multiple surgical factors, such as surgical trauma, inflammation, pain, anesthetics, blood transfusion, ischemia, etc., can negatively affect the balance between metastasis and immune surveillance in the perioperative period $[39,40$, 41]. However, each effect can be modulated by neuraxial anesthesia, which can help to preserve immune function $[1,2]$. The activation of the autonomic nervous system and the hypothalamic-pituitary-adrenal axis (HPA axis) releases more neuroendocrine stress, which may lead to immunosuppression during the perioperative period [42, 43]. Surgery also can reduce NK cell numbers, suppress immunity, facilitate the growth of preexisting micrometastases, and disseminate malignant cells during tumor manipulation $[44,45]$. Anesthesia may impair numerous functions, including neutrophil, macrophage, dendritic cell, T lymphocyte, and NK cell functions [46]. Opioids can produce immunosuppression by reducing NK cells, inhibiting lymphocyte proliferation, and altering cytokine expression $[4,5]$. They can also promote angiogenesisdependent tumor growth through the $\mu$ receptors present on endothelial cells [47]. Neuraxial anesthesia can attenuate neuroendocrine stress by cutting off afferent neural transmission from reaching the central nervous system and blocking descending efferent activation of the sympathetic nervous system [42, 43, 48]. It can reduce anesthetic requirements, decrease the release of endogenous opioids, improve tissue oxygenation, and promote innate anti-tumor factors through the effects of local anesthetic $[7,8,49,50]$. It can also bring early survival benefit by reducing the incidence of thrombotic events, infection, cardiovascular and pulmonary complications [51, 52]. Therefore, neuraxial anesthesia (combined with or without GA) may bring about better outcomes regarding tumor growth and metastasis.

Our results suggest that neuraxial anesthesia maybe associated with improved OS in patients with cancer surgery, especially for those patients with colorectal 
A

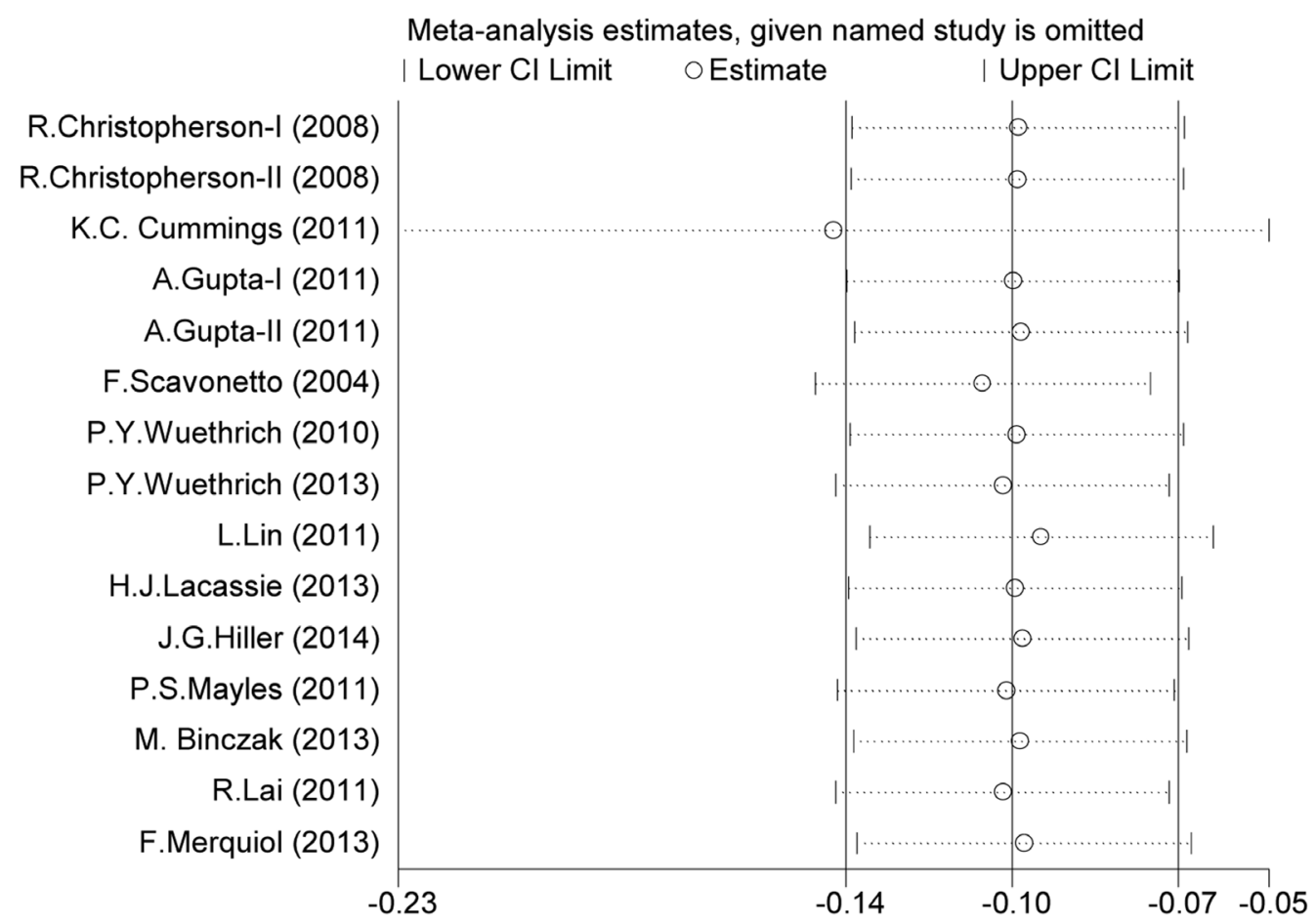

B

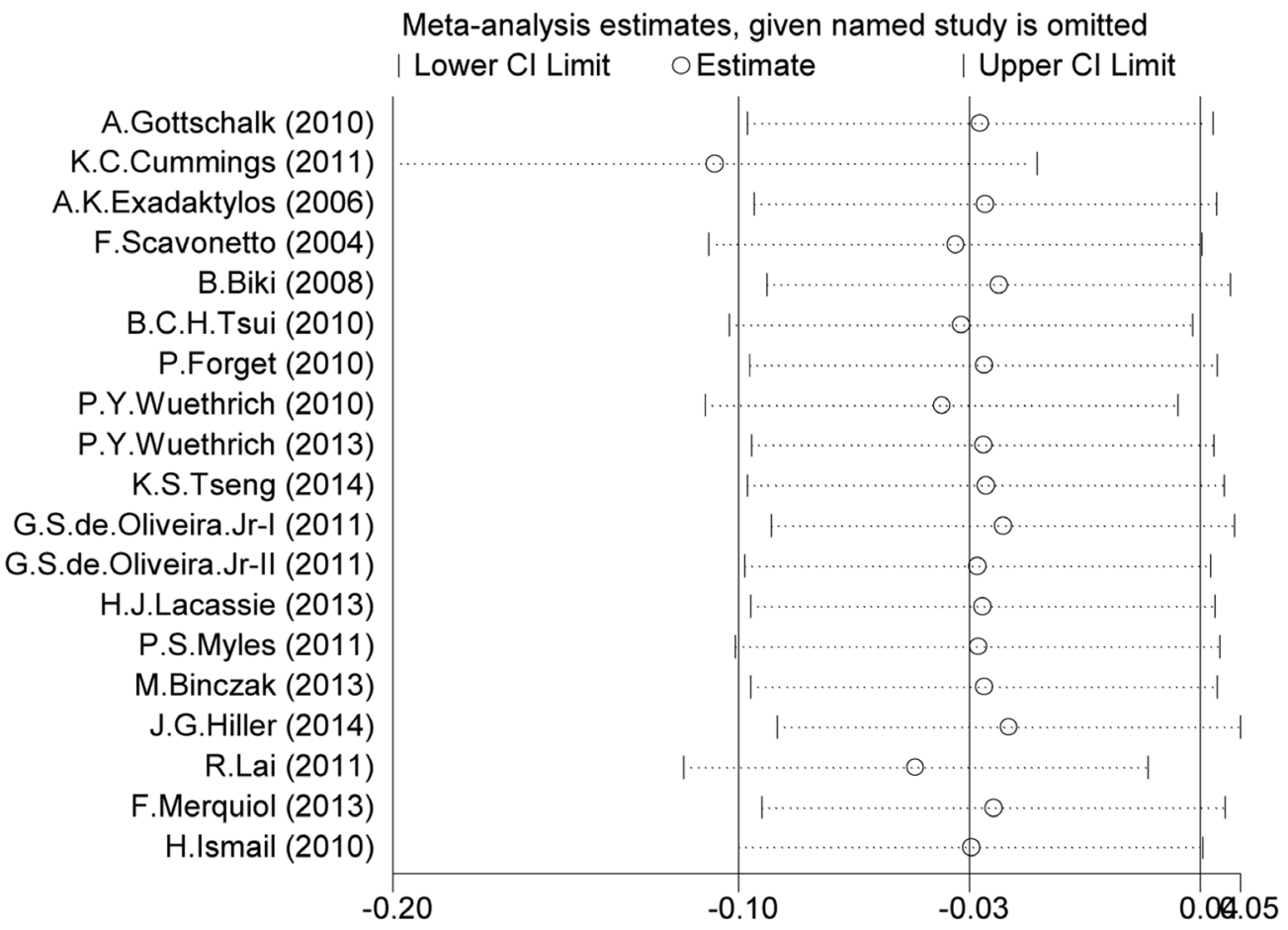

Figure 3: Sensitivity analysis of meta-analysis. Figure 3A shows the influence of individual studies on the summary HR for OS. Figure 3B shows the influence of individual studies on the summary HR for RFS. 
A

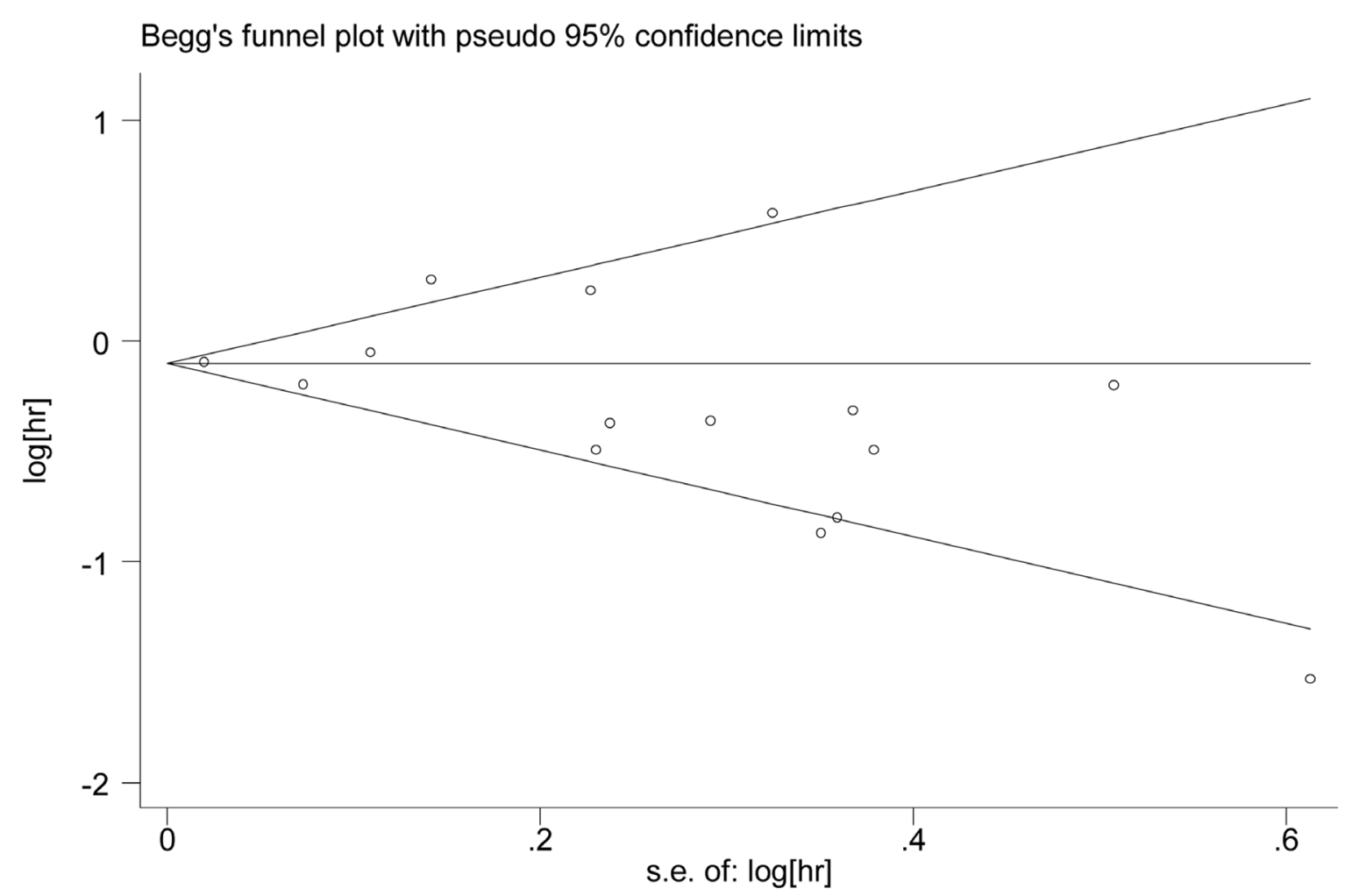

B

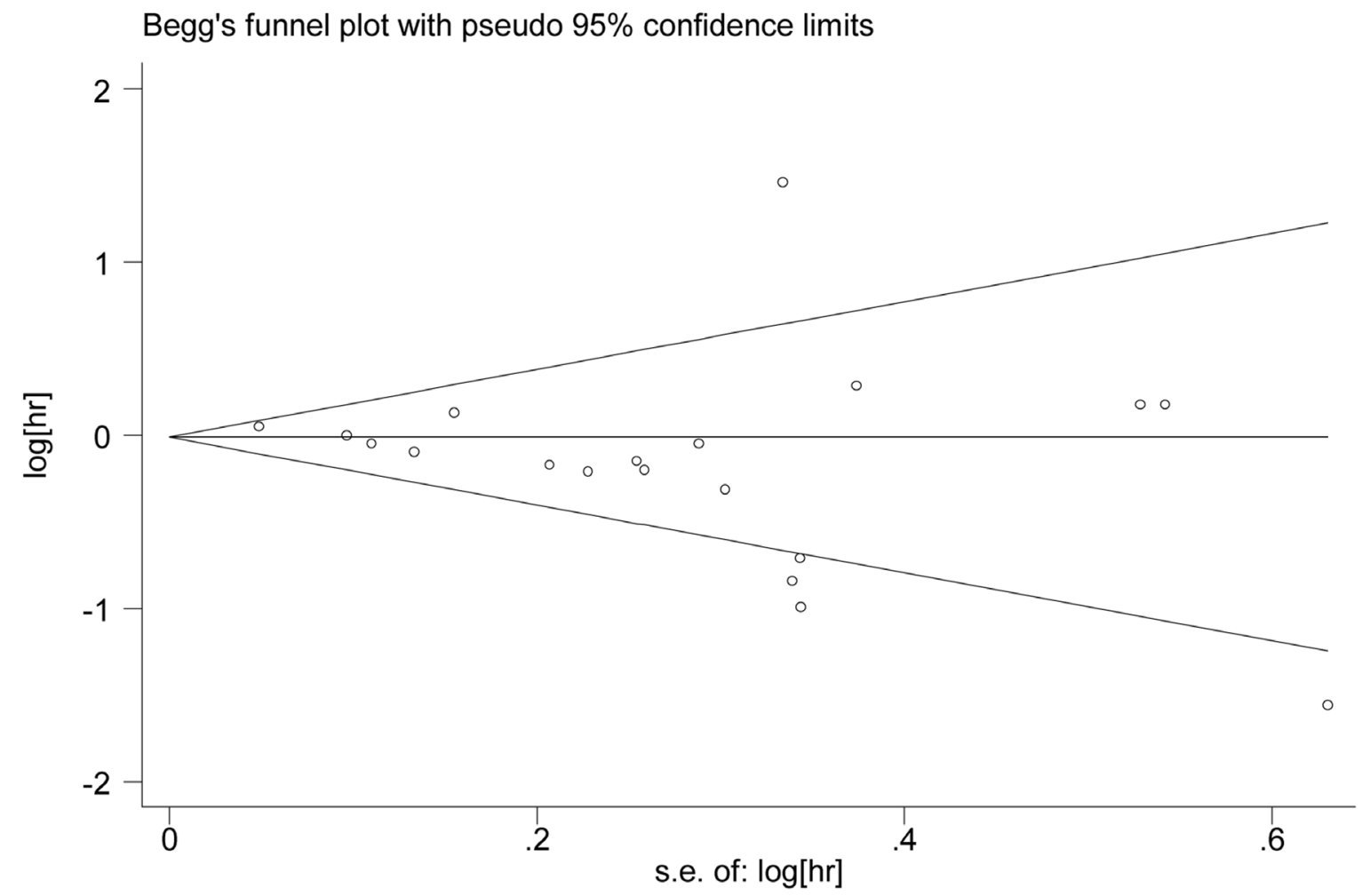

Figure 4: Publication bias plots. Figure 4A and 4B show the Begg's test funnel plots of studies included in the meta-analysis for OS and RFS. 
cancer. However, studies in patients undergoing colorectal surgery have found inconsistent results. Christopherson et al. [9-11, 53] found that epidural anesthesia may improve survival among patients with non-metastatic colon cancer before 1.46 years, but it had no impact on patient survival with metastatic colon cancer [9]. Gupta et al. found a reduction in all-mortality after rectal cancer but not colon cancer in patients with epidural usage [11].Cummings et al. showed that epidural use is associated with improved survival in patients with colorectal cancer, but an association between epidural use and decreased cancer recurrence is not supported [10]. However, another study did not identify any benefit with epidural analgesia for OS after laparoscopic colorectal resection [53]. Our results are also in accordance with those from a previous metaanalysis in our institution by Chen et al., which confirmed the beneficial impact of neuraxial anesthesia on colorectal cancer survival [37]. We speculate that colorectal cancer may be more sensitive to the immune protective effect of neuraxial anesthesia.

Our results also suggest a significant association between neuraxial anesthesia and reduced cancer recurrence. Neuraxial anesthesia has been reported to decrease the recurrence rate after surgery for breast cancer (paravertebral block), prostate cancer (thoracic epidural analgesia), ovarian cancer (epidural anesthesia/analgesia), hepatocellular cancer (epidural anesthesia), laryngeal and hypopharyngeal cancer (cervical epidural anesthesia and analgesia), and gastro-oesophageal cancer (epidural analgesia) [17, 20, 21, 23, 24, 28], whereas other studies reported no association between neuraxial anesthesia and cancer recurrence [10, 12-14, 16, 18, 19, 22, 25-29]. Our results are in contrast to those in two previous metaanalyses by Chen et al. and Pei et al [30, 37]. We could not confirm the results observed by Pei et al., as they failed to include all eligible studies available at the time of analysis. Their results' lack of significance is likely due to the limited study number. In the two years since that analysis, a great number of clinical studies focusing on the association between neuraxial anesthesia and oncological outcome have emerged. For our current study, more prospective and retrospective studies were collected to assess this important clinical problem. Our meta-analysis is an update to the study by Chen et al.

Our study does have some unavoidable limitations. First, different types of cancer have different tumor biological characteristics (e.g., the type and the site of tumor, cancer staging and adjuvant therapy), and whether our conclusions can be applied to them all is unknown. Second, the limited number of studies makes the results of subgroup analysis less reliable. Moreover, there is only one study for some cancers, such as breast cancer, gastroesophageal cancer, laryngeal and hypopharyngeal cancer, cervical cancer, and hepatocellular carcinoma. Third, some other confounding variables are not controlled in this meta-analysis, such as different surgical techniques, difficulty in defining relapse, various patient populations, different length of follow-up and various timing of epidural use. Fourth, our systemic review is also restricted by the nonrandomized and retrospective nature of the studies. Moreover, we only selected studies published in English, which would lead to so-called "English language bias" that may reduce the accuracy of our results.

In conclusion, our meta-analysis suggests that neuraxial anesthesia may be associated with improved OS in patients with cancer surgery, especially for these patients with colorectal cancer. Our results also support a potential association between neuraxial anesthesia and a reduced risk of cancer recurrence. Our finding should be interpreted with considerable caution, and more prospective studies are needed to elucidate whether neuraxial anesthesia has an effect on cancer-specific outcome in patients undergoing cancer surgery.

\section{MATERIALS AND METHODS}

\section{Study identification and data extraction}

Literature was retrieved through the PubMed, Web of Science, EMBASE database, and the Cochrane Database of Systematic Reviews (updated to August-1, 2015) using the following keywords: (i) "neuraxial anesthesia," "epidural anesthesia," "spinal anesthesia," "regional anesthesia,"“anesthetic technique," or "general anesthesia," and (ii) "recurrence," "metastasis," "survival," or "prognosis," and (iii) "neoplasm,"“cancer," or"carcinoma". Only studies published in English were included. Both abstracts and full text papers were eligible. We did not define the minimum number of patients to be included for this meta-analysis. Three hundred and eighteen papers were screened out by this strategy. After reviewing their titles, we identified 97 papers for further consideration. And after reading their abstracts, we finally reviewed 47 potentially eligible papers by full text reading. The study flowchart is shown in Figure 1.

The included studies should meet the following criteria: (i) evaluating the effect of neuraxial anesthesia (combined with or without GA) and GA on oncological outcome after cancer surgery, (ii) independent prospective or retrospective study, and (iii) having hazard ratios (HR) with 95\% confidence intervals (CIs) (or having adequate available data to calculate). As most other studies suggested [31, 32], we extracted the HR adjusted for other potentially suspected factors. The adjusted HRs, rather than crude odd ratios or relative risks, might be more dependable to reflect the impact of anesthetic technique on oncological outcome. As a result, we identified 21 eligible studies for this systemic review. The following variables were extracted from each study if available: first author's name, publication year, cancer type, design type, survival 
type, numbers in neuraxial anesthesia group, numbers in GA group, and HR with 95\% CIs of treatment outcomes.

Two authors (M.L.W and W.K.C) collected the information carefully and independently. We used the 9-star Newcastle-Ottawa Scale to evaluate the study quality (The Newcastle-Ottawa Scale for assessing the quality of nonrandomized studies in systemic review. [33] Ottawa, Canada: Dept. of Epidemiology and Community Medicine, University of Ottawa. http://www.ohri.ca/ programs/clinical_epidemiology/oxford.htm. Accessed on 2015 Jan 1).

\section{Statistical analysis}

This systematic review and meta-analysis was carried out in compliance with the PRISMA statement for reporting meta-analysis [34, 35]. For each study, HR along with its $95 \%$ CIs was recorded to evaluate the association between neuraxial anesthesia and oncological outcomes. The heterogeneity among studies was checked by Cochran chi-square Q statistics or $\mathrm{I}^{2}$ statistics, which decided the use of fixed-effects model or random-effects model. When $P$-value $<0.05$ or I-square $>25 \%$, heterogeneity was considered and the random-effects model was chosen to calculate HR using the DerSimonian and Laird method. Otherwise, the fixed-effects model was applied using the Mantel-Haenszel method [36]. We conducted subgroup analysis according to cancer type. We also performed sensitivity analysis by omitting each study to find potential outliers. The publication bias was examined visually in a funnel plot of In [OR] against its standard error (SE), and the degree of asymmetry was tested using Egger's test and Begg's test. A symmetrical plot $(P$-value $>0.05)$ suggested no publication bias. All of the statistical analyses were calculated using Stata/SE version 12.0 (Stata Corporation, College Station, TX).

\section{ACKNOWLEDGMENTS}

We would like to thank Yuezhen Dai for editing this manuscript, as well as Ziqing $\mathrm{Xu}$, Xiazhen Dong, Weixing $\mathrm{Xu}$ and Songyuan Weng for their assistance in the preparation of this manuscript. This research was supported by the hospital foundation (YJ201415), the State Key Basic Research Program (973) project (2015CB553404).

\section{CONFLICTS OF INTEREST}

There is no conflict of interest.

\section{REFERENCES}

1. Ben-Eliyahu S. The promotion of tumor metastasis by surgery and stress: immunological basis and implications for psychoneuroimmunology. Brain Behav Immun. 2003; 17: S27-S36.

2. Melamed R, Rosenne E, Shakhar K, Schwartz Y, Abudarham N, Ben-Eliyahu S. Marginating pulmonary-NK activity and resistance to experimental tumor metastasis: suppression by surgery and the prophylactic use of a beta-adrenergic antagonist and a prostaglandin synthesis inhibitor. Brain Behav Immun. 2005; 19: 114-126.

3. Brand JM, Kirchner H, Poppe C, Schmucker P. The effects of general anesthesia on human peripheral immune cell distribution and cytokine production. Clin Immunol Immunopathol. 1997; 83: 190-194.

4. Markovic SN, Knight PR, Murasko DM. Inhibition of interferon stimulation of natural killer cell activity in mice anesthetized with halothane or isoflurane. Anesthesiology. 1993; 78: 700-706.

5. Beilin B, Shavit Y, Hart J, Mordashov B, Cohn S, Notti I, Bessler H. Effects of anesthesia based on large versus small doses of fentanyl on natural killer cell cytotoxicity in the perioperative period. Anesth Analg. 1996; 82: 492-497.

6. Yeager MP, Colacchio TA, Yu CT, Hildebrandt L, Howell AL, Weiss J, Guyre PM. Morphine inhibits spontaneous and cytokine-enhanced natural killer cell cytotoxicity in volunteers. Anesthesiology. 1995; 83: 500-508.

7. Bar-Yosef S, Melamed R, Page GG, Shakhar G, Shakhar K, Ben-Eliyahu S. Attenuation of the tumor-promoting effect of surgery by spinal blockade in rats. Anesthesiology. 2001; 94: 1066-1073.

8. Snyder GL, Greenberg S. Effect of anaesthetic technique and other perioperative factors on cancer recurrence. Br J Anaesth. 2010; 105: 106-115.

9. Chrisopherson R, James KE, Tableman M, Marshall P, Johnson FE. Long-term survival after colon cancer surgery: a variation association with choice of anesthesia. Anesth Analg. 2008; 107: 325-332.

10. Cummings $\mathrm{KC}$ 3rd, Xu F, Cummings LC, Cooper GS. A comparison of epidural analgesia and traditional pain management effects on survival and cancer recurrence after colectomy: a population-based study. Anesthesiology. 2012; 116:797-806.

11. Gupta A, Björnsson A, Fredriksson M, Hallböök O, Eintrei C. Reduction in mortality after epidural anaesthesia and analgesia in patients undergoing rectal but not colonic cancer surgery: a retrospective analysis of data from 655 patients in central Sweden. Br J Anaesth. 2011; 107: 164170.

12. Scavonetto F, Yeoh TY, Umbreit EC, Weingarten TN, Gettman MT, Frank I, Boorjian SA, Karnes RJ, Schroeder DR, Ranqel LJ, Hanson AC, Hofer RE, Sessler DI, et al. Association between neuraxial analgesia, cancer progression, and mortality after radical prostatectomy: a large, retrospective matched cohort study. Br J Anaesth. 2014; 113: i95-i102.

13. Wuethrich PY, Hsu Schmitz SF, Kessler TM, Thalmann 
GN, Studer UE, Stueber F, Burkhard FC. Potential influence of the anesthetic technique used during open radical prostatectomy on prostate cancer-related outcome: a retrospective study. Anesthesiology. 2010; 113: 570-576.

14. Wuethrich PY, Thalmann GN, Studer UE, Burkhard FC. Epidural analgesia during open radical prostatectomy does not improve long-term cancer-related outcome: a retrospective study in patients with advanced prostate cancer. PLoS One. 2013; 8: e72873.

15. Lin L, Liu C, Tan H, Ouyang H, Zhang Y, Zeng W. Anaesthetic technique may affect prognosis for ovarian serous adenocarcinoma: a retrospective analysis. $\mathrm{Br} \mathrm{J}$ Anaesth. 2011; 106: 814-822.

16. Lacassie HJ, Cartagena J, Brañes J, Assel M, Echevarría GC. The relationship between neuraxial anesthesia and advanced ovarian cancer-related outcomes in the Chilean population. Anesth Analg. 2013; 117: 653-660.

17. Hiller JG, Hacking MB, Link EK, Wessels KL, Riedel BJ. Perioperative epidural analgesia reduces cancer recurrence after gastro-oesophageal surgery. Acta Anaesthesiol Scand. 2014; 58: 281-290.

18. Myles PS, Peyton P, Silbert B, Hunt J, Rigg JR, Sessler DI; ANZCA Trials Group Investiqators. Perioperative epidural analgesia for major abdominal surgery for cancer and recurrence-free survival: randomised trial. BMJ. 2011; 342: d1491.

19. Binczak. M, Tournay E,Billard V, Rey A, Jayr C. Major abdominal surgery for cancer: Does epidural analgesia have a long-term effect on recurrence-free and overall survival? Ann Fr Anesth Reanim. 2013; 32: e81-e88.

20. Lai R, Peng Z, Chen D, Wang X, Xing W, Zeng W, Chen M. The effect of anesthetic technique on cancer recurrence in percutaneous radiofrequency ablation of small hepatocellular carcinoma. Anesth Analg. 2012; 114: 290296.

21. Merquiol F, Montelimard AS, Nourissat A, Molliex S, Zufferey PJ. Cervical epidural anesthesia is associated with increased cancer-free survival in laryngeal and hypopharyngeal cancer surgery: a retrospective propensitymatched analysis. Reg Anesth Pain Med. 2013; 38:398-402.

22. Gottschalk A, Ford JG, Regelin CC, You J, Mascha EJ, Sessler DI, Durieux ME, Nemergut EC. Association between epidural analgesia and cancer recurrence after colorectal cancer surgery. Anesthesiology. 2010; 113: 2734.

23. Exadaktylos AK, Buggy DJ, Moriarty DC, Mascha E, Sessler DI. Can anesthetic technique for primary breast cancer surgery affect recurrence or metastasis? Anesthesiology. 2006; 105: 660-664.

24. Biki B, Mascha E, Moriarty DC, Fitzpatrick JM, Sessler DI, Buggy DJ. Anesthetic technique for radical prostatectomy surgery affects cancer recurrence: a retrospective analysis. Anesthesiology. 2008; 109: 180-187.

25. Tsui BC, Rashiq S, Schopflocher D, Murtha A, Broemling
S, Pillay J, Finucane BT. Epidural anesthesia and cancer recurrence rates after radical prostatectomy. Can J Anesth. 2010; 57: 107-112.

26. Forget $\mathrm{P}$, Tombal B, Scholtès JL, Nzimbala J, Meulders C, Legrand C, Van Cangh P, Cosyns JP, De Kock M. Do intraoperative analgesics influence oncological outcomes after radical prostatectomy for prostate cancer? Eur J Anaesthesiol. 2011; 28: 830-835.

27. Tseng KS, Kulkarni S, Humphreys EB, Carter HB, Mostwin JL, Partin AW, Han W, Wu CL. Spinal anesthesia does not impact prostate cancer recurrence in a cohort of men undergoing radical prostatectomy: an observational study. Reg Anesth Pain Med. 2014; 39: 284-288.

28. de Oliveira GS Jr, Ahmad S, Schink JC, Singh DK, Fitzgerald PC, McCarthy RJ. Intraoperative neuraxial anesthesia but not postoperative neuraxial analgesia is associated with increased relapse-free survival in ovarian cancer patients after primary cytoreductive surgery. Reg Anesth Pain Med. 2011; 36: 271-277.

29. Ismail H, Ho KM, Narayan K, Kondalsamy-Chennakesavan $\mathrm{S}$. Effect of neuraxial anaesthesia on tumour progression in cervical cancer patients treated with brachytherapy: a retrospective cohort study. Br J Anaesth. 2010; 105: 145149.

30. Pei L, Tan G, Wang L, Guo W, Xiao B, Gao X, Wang L, Li H, Xu Z, Zhang X, Zhao J, Yi J, Huang Y. Comparison of combined general-epidural anesthesia with general anesthesia effects on survival and cancer recurrence: a meta-analysis of retrospective and prospective studies. PLoS One. 2014; 9: e114667.

31. Biagi JJ, Raphael MJ, Mackillop WJ, Kong W, King WD, Booth CM. Association between time to initiation of adjuvant chemotherapy and survival in colorectal cancer: a systemic review and mata-analysis. JAMA. 2011; 305:2335-2342.

32. Larsson SC, Orsini N, Wolk A. Vitamin B6 and risk of colorectal cancer: a meta-analysis of prospective studies. JAMA. 2010; 303: 1077-1083.

33. Liberati A, Altman DG, Tetzlaff J, Mulrow C, Gøtzsche PC, Ioannidis JP, Clarke M, Devereaux PJ, Kleijnen J, Moher D. The PRISMA statement for reporting systemic reviews and meta-analyses of studies that evaluate health care interventions: explanation and elaboration. J Clin Epidemiol. 2009; 62: e1-e34.

34. Higgins J, Green Se. (updated March 2011) Cochrane Handbook for Systematic Reviews of Interventions Version 5.1.0. The Cochrane Collaboration, 2011. Available: www. cochrane-handbook.org. Accessed 2013 January 1.

35. Higgins JP, Thompson SG, Deeks JJ, Altman DG. Measuring inconsistency in meta-analyses. BMJ. 2003; 327:557-560.

36. Wells G, Shea B, O'Connell D. The Newcastle-Ottawa Scale (NOS) for assessing the quality of nonrandomized studies in meta-analyses. Ottawa: Ottawa Hospital Research 
Institute; 2011. Oxford. asp.

37. Chen WK, Miao CH. The effect of anesthetic technique on survival in human cancers: a meta-analysis of retrospective and prospective studies. PLoS One. 2013; 8: e56540.

38. Brittenden J, Heys SD, Ross J, Eremin O.Natural killer cells and cancer. Cancer. 1996; 77: 1226-1243.

39. Shakhar G, Ben-Eliyahu S. Potential prophylactic measures against postoperative immunosuppression: could they reduce recurrence rates in oncological patients? Ann Surg Oncol. 2003; 10: 972-992.

40. Smyth MJ, Godfrey DI, Trapani JA. A fresh look at tumor immunosurveillance and immunotherapy. Nat Immunol. 2001; 2: 293-299.

41. Lutgendorf SK, Cole S, Costanzo E, Bradley S, Coffin J, Jabbari S, Rainwater K, Ritchie JM, Yang M, Sood AK. Stress-related mediators stimulate vascular endothelial growth factor secretion by two ovarian cancer cell lines. Clin Cancer Res. 2003; 9: 4514-4521.

42. Buggy DJ, Smith G. Epidural anaesthesia and analgesia: better outcome after major surgery? Growing evidence suggests so. BMJ. 1999;319: 530-531.

43. O'Riain SC, Buggy DJ, Kerin MJ, Watson RW, Moriarty DC. Inhibition of the stress response to breast cancer surgery by regional anesthesia and analgesia does not affect vascular endothelial growth factor and prostaglandin E2. Anesth Analg. 2005; 100: 244-249.

44. Wong IH, Lau WY, Leung T, Yeo W, Johnson PJ. Hematogenous dissemination of hepatocytes and tumor cells after surgical resection of hepatocellular carcinoma: a quantitative analysis. Clin Cancer Res. 1999; 5: 4021-4027.

45. Antoni $\mathrm{MH}$, Lutgendorf SK, Cole SW, Dhabhar FS, Sephton SE, McDonald PG, Stefanek M, Sood AK. The influence of bio-behavioural factors on tumour biology: pathways and mechanisms. Nat Rev Cancer. 2006; 6: 240248.

46. Wrona D. Neural-immune interactions: an integrative view of the bidirectional relationship between the brain and immune systems. J Neuroimmunol. 2006; 172: 38-58.

47. Gupta K, Kshirsagar S, Chang L, Schwartz R, Law PY, Yee D, Hebbel RP. Morphine stimulates angiogenesis by activating proangiogenic and survival-promoting signaling and promotes breast tumor growth. Cancer Res. 2002; 62: 4491-4498.

48. Ahlers O, Nachtigall I, Lenze J, Goldmann A, Schulte E, Höhne C, Fritz G, Keh D. Intraoperative thoracic epidural anaesthesia attenuates stress-induced immunosuppression in patients undergoing major abdominal surgery. Br J Anaesth. 2008; 101: 781-787.

49. Ben-Eliyahu S, Page GG, Yirmiya R, Shakhar G.Evidence that stress and surgical interventions promote tumor development by suppressing natural killer cell activity. Int J Cancer. 1999; 80: 880-888.

50. Chae BK, Lee HW, Sun K, Choi YH, Kim HM. The effect of combined epidural and light general anesthesia on stress hormones in open heart surgery patients. Surg Today 1998; 28: 727-731.

51. Rodgers A, Walker N, Schug S, McKee A, Kehlet H, van Zundert A, Sage D, Futter M, Saville G, Clark T, MacMahon S. Reduction of postoperative mortality and morbidity with epidural or spinal anaesthesia: results from overview of randomized trial. BMJ. 2000; 321: 1493.

52. Park WY, Thompson JS, Lee KK. Effect of epidural anesthesia and analgesia on perioperative outcome: a randomized, controlled Veterans Affairs Cooperative Study. Ann Surg. 2001; 234: 560-571.

53. Day A, Smith R, Jourdan I, Fawcett W, Scott M, Rockall T. Retrospective analysis of the effect of postoperative analgesia on survival in patients after laparoscopic resection of colorectal cancer. Br J Anaesth. 2012; 109: 185-190. 